Compartive Analysis of Job Involvemnet in Relation to Organizarional Health

Prof. B.L.Lakkanavar, Hanamant Ummanna

\title{
Comparative Analysis of Job Involvement in Relation to Organizational Health of Secondary School Teachers in Hydrabad Karnataka
}

\author{
Prof. B.L.Lakkanavar \\ Registrar, Karnatak State Rural Development and Panchayat Raj University, \\ Gadag, Karnatak \\ Email: bllakkannavar@rediffmail.com \\ Hanamant Ummanna \\ Research Scholar \\ Email:hanamanthkonda68@gmail.com
}

\begin{abstract}
"A healthy organization in this sense not only survives in its environment but also continues to cope adequately with time and continuously develops and extends its surviving and coping abilities. the problem of assessment of teaching effectiveness students' point of view, analyzing the questionnaire given to the students I the University of Udine at the end of their courses. The problem, in statistical terms, is to relate an "outcome variable (the dependent one), in this case, ratings given by the students or a particular linear combination of it to a set of explanatory variables both to the student and teacher level. The study is based on secondary data. In this Paper Focused on reveals that the obtained ' $t$ ' value (3.1428) is greater than the tabled ' $t$ ' value at 0.05 level. It is therefore concluded that the two groups differ significantly with respect to the variable under consideration. the obtained' value (2.8769) is greater than the tabled ' $t$ ' value at 0.05 level. It is therefore concluded that the two groups differ significantly with respect to the variable under consideration. This implies that the two groups differ significantly in respect of their opinion about the organizational health of the secondary schools. This shows that the mean value of rural teachers is greater than that of urban teachers. This indicates that the teachers have a good opinion regarding the organizational health of the secondary schools.
\end{abstract}

Keywords: Job Involvement, Teachers and Factors Contributing
Reference to this paper should be made as follows:

Received: 15.07.2020

Approved: 28.09.2020

Prof. B.L.Lakkanavar, Hanamant Ummanna

Comparative Analysis of Job Involvement in Relation to Organizational Health of Secondary School Teachers in Hydrabad Karnataka

Article No. 24

RJPSS Sept. 2020, Vol. XLVNo. 2, pp. 208-215

Online available at: https://anubooks.com/rjpss2020-vol-xlv-no-2 https://doi.org/10.31995/ rjpss.2020.v45i01.024 
RJPSS Sept. 2020 Vol. XLV No.2, ISSN: (P)0258-1701 (e)2454-3403 Impact Factor: 7.717

https://doi.org/10.31995/rjpss.2020.v45i01.024

\section{INTRODUCTION}

"A healthy organization in this sense not only survives in its environment but also continues to cope adequately with time and continuously develops and extends its surviving and coping abilities, short-run operation on any particular day may be effective or ineffective, but continued survival adequate coping and growth are taking place."

This study considers the problem of assessment of teaching effectiveness students' point of view, analyzing the questionnaire given to the students I the University of Udine at the end of their courses. The problem, in statistical terms, is to relate an "outcome variable (the dependent one), in this case, ratings given by the students or a particular linear combination of it to a set of explanatory variables both to the student and teacher level. The data set used in the analysis consists of almost 9500 questionnaires regarding 416 courses of the University of Udine covering the academic year 1999-2000 its structure (questionnaires clustered in courses) suggest the use of a particular class of regression models, the multilevel models.

Sarget (2003) investigated on "Keeping Teachers Happy Job Satisfaction Among Primary school Teachers in Rural China". Teachers are a crucial element of educational opportunity structures. In China, the recent opening up of labor markets in general and within the school system has raised concerns about retaining qualified teachers in schools serving of communities. This paper considers the question, what factors keep teachers serving poor communities satisfied with their work?.

The co-curricular activities in the new system of education have quite an important place. It is felt that participation in co-curricular activities helps in the growth of a well-balanced and well-adjusted personality. It creates a group feeling of one's brotherhood, broadens the outlook that develops a catholicity and spirit and tolerance, which are necessary for good citizenship. To ensure the all-round development of students, a teacher has also to organize such co-curricular activities as games, sports, quiz excursions, tours, field trips, etc. These activities include common observance, sports, plays art shows, excursions, and picnics.

\section{REVIEW OF LITERATURE}

Mutmainah's (2013) Organizational Culture, Leadership Style Influence on Organizational Commitment and Performance of Teachers, the purpose of this study to analyze the direct and indirect effects of organizational health and leadership style on organizational commitment and performance of private senior high school teachers of Malang town. Sampling technique using proportional random sampling. Number of samples obtained by the 158 respondents. 
Compartive Analysis of Job Involvemnet in Relation to Organizarional Health

Prof. B.L.Lakkanavar, Hanamant Ummanna

Patil (2013) undertook "A study of the relationship between Job Satisfaction and and Job Involvement of Teachers of Secondary Schools". The results of the study were (i) The female teachers of secondary schools are higher on job satisfaction as compared to male teachers. (ii) The female teachers of secondary schools are higher on the physical facilities dimension of job satisfaction as compared to male teachers of secondary schools are higher on job involvement as compare to male teachers.

Wibere (2014): Studies interactive relationship between job involvement, job satisfaction, organizational citizenship behavior, and organizational commitment in Nigerian universities. The study examined the interactive relationship between job involvement, job satisfaction, organizational commitment citizenship behavior (OCB), and organizational commitment among employees of Nigerian universities.

\section{METHODOLOGY OF THE STUDY}

\section{Government Schools:}

Government schools are those where the rules, regulations, functions, appointments, and finance are the responsibility of the government of Karnataka.

\section{Private Aided Schools:}

The schools run and are owned by private management and the overall finance, rules, and regulations is that of government.

\section{Private Unaided Schools:}

The schools which are fully owned run and financed by the private management.

\section{Gender:}

Both male and female teachers were considered in this study.

Age

Three levels of age groups are considered in the present study

a) Teachers with 25-29years of age

b) Teachers with 30-34 years of age

c) Teachers with 35 and above years of age

\section{Teaching Experience}

Two different groups of teaching experience (1-10 years and 11 and above years) are considered in the present study.

\section{Variables}

The following variables are considered for the present study.

\section{Independent Variables}

i) Age groups (25-29, 30-34, 35 and above) 
RJPSS Sept. 2020 Vol. XLV No.2, ISSN: (P)0258-1701 (e)2454-3403 Impact Factor: 7.717

ii) Gender (Male and Female)

iii) Type of Management (Unaided/Aided/Government)

iv) Teaching Experience (1-10 years and 11 and above years)

\section{Dependent Variables}

i) Job Involvement

ii) Organizational Health

\section{Limitations of the Study}

1) The present study is confined to Hyderabad Karnataka District only.

2) The study is districted to secondary school teachers only.

3) The present study is confined to Age, Gender, Types of Management, and Teaching Experience of the teachers.

\section{OBJECTIVES OF THE STUDY}

- To examine the job involvement in relation to the organizational health of secondary school teachers in Hyderabad Karnataka.

- Factors influencing the Development of attitude to increasing the education status in Hyderabad Karnataka.

- Conclusion and policy suggestion

\section{RESULT AND DISCUSSION}

- Job involvement in relation to the organizational health of secondary school teachers in Hyderabad Karnataka.

Table-1 Comparison of Mean, SD and ' $t$ ' Value of Arts and Science Subject Teachers

\begin{tabular}{|c|c|c|c|c|c|}
\hline Variable & Mean & S.D & t-Value & p-Value & Significance \\
\hline Arts Teachers & 27.4 & 2.98 & & & \\
\hline Science Teachers & 26.2 & 2.88 & 3.1428 & $<0.05$ & Significant \\
\hline
\end{tabular}

The above table reveals that the obtained' $t$ ' value (3.1428) is greater than the tabled ' $t$ ' value at 0.05 level. It is therefore concluded that the two groups differ significantly with respect to the variable under consideration. This implies that the two groups differ significantly in respect of their opinion about the organizational health of the secondary schools. This shows that the mean value teacher with Arts subject is greater than that of teachers with Science subjects. This indicates that the teachers with art background have better opinions regarding the organizational health 
Compartive Analysis of Job Involvemnet in Relation to Organizarional Health

Prof. B.L.Lakkanavar, Hanamant Ummanna

of the secondary schools than the teachers with a science background. Arts and science teachers differ significantly in respect of their opinion regarding the organizational health of the secondary schools. However, Arts teachers have a better opinion regarding the organizational health of the schools than the science teachers.

Table-2 Comparison of Mean, SD, and ' $t$ ' Value of Rural and Urban Teachers (Organizational Health of Secondary Schools).

\begin{tabular}{|l|r|r|r|r|r|}
\hline Variable & \multicolumn{1}{|l|}{ Mean } & S.D & t-Value & p-Value & Significance \\
\hline Rural Teachers & 21.9725 & 2.46 & & & \\
\cline { 1 - 3 } Urban Teachers & 20.0108 & 2.47 & 2.88 & $<0.05$ & Significant \\
\hline
\end{tabular}

The above table reveals that the obtained' value (2.8769) is greater than the tabled ' $t$ ' value at 0.05 level. It is therefore concluded that the two groups differ significantly with respect to the variable under consideration. This implies that the two groups differ significantly in respect of their opinion about the organizational health of the secondary schools. This shows that the mean value of rural teachers is greater than that of urban teachers. This indicates that the teachers have a good opinion regarding the organizational health of the secondary schools.

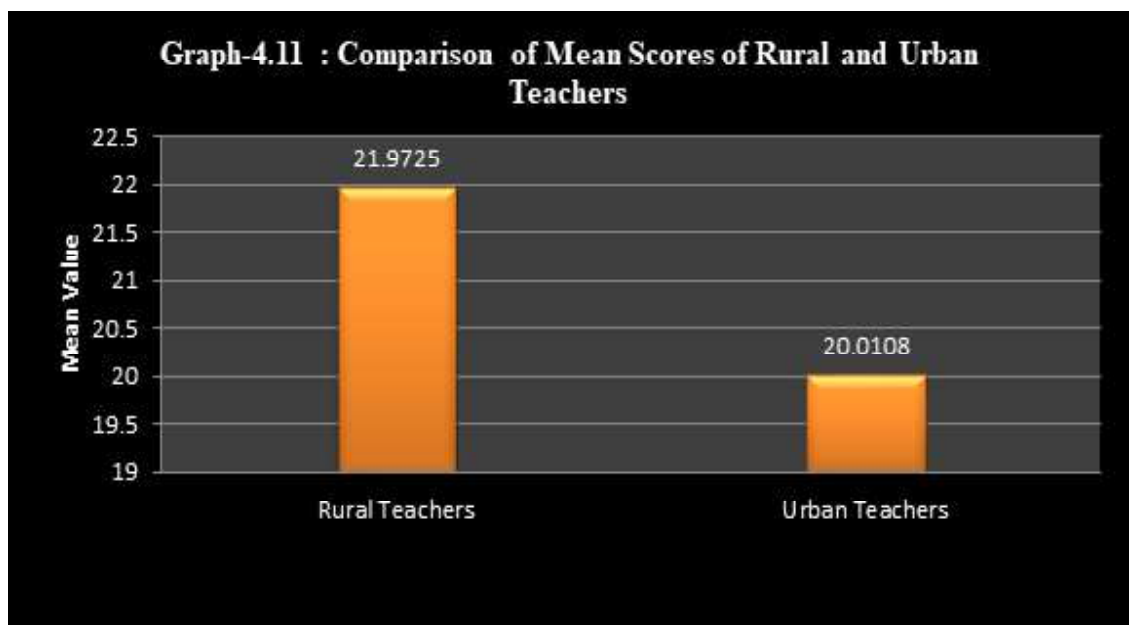

Rural and urban teachers do not differ significantly in respect of their opinion regarding the organizational health of the secondary schools. However, rural teachers have the least opinion regarding the organizational health of the schools than urban teachers. 
RJPSS Sept. 2020 Vol. XLV No.2, ISSN: (P)0258-1701 (e)2454-3403 Impact Factor: 7.717

https://doi.org/10.31995/rjpss.2020.v45i01.024

\section{Factors influencing the Development of attitude to increasing the education status in Hyderabad Karnataka.}

As mentioned earlier 'attitudes are acquired once the development of attitude is influenced by many factors. Following are some of the important factors.

\section{$>$ Sex}

It is a well known fact that attitudes are reactions to something. There is no uniform pattern of attitude among the different people. This difference is remarkable with respect to the sex of an individual. It seems that there also some important sex differences in the development of emotions. Endo chronological effect may be one of the main reasons.

As an example of specific sex differences in personality and attitudes, it is worthwhile to mention the study made by Tyron (1930) she found that at the age of twelve the average girl wished to conform to adult standards and to be ladylike; but by the age of fifteen, the characteristics desire was rather to be attractive to men and to be considered a good support certainly this is hardly what would be found in a comparison of boys at twelve and fifteen.

Another important sex difference is shown by the Allport-Vernon study of values. On this test makes receive higher scores for aesthetic, social, and religious values. Quite obviously these and the other sex differences in interest and values will have an important effect on the result of instructions.

\section{$>$ Age}

Generally, we all felt that the person varies according to the age. Common observation of everyone is that older people and younger people differ in their attitude towards many things. This is commonly known as the 'generation gap'.

\section{$>$ Home Influence}

It is generally accepted that attitudes are determined largely by the social environment and that home influences are especially important. In a study of intrafamily similarities in attitudes, New Comb and Svehla compared parents and children on Thurston's Scale for measuring attitudes towards the church, towards war, and towards communism. Corrections between the parents were highest, those between parents and children were next, and those between siblings were lowest.

\section{$>$ Government School}

The form of the school government seems to be an important factor in determining attitudes both towards the government itself and towards other things. In an experimental study, Lewin and Lippitt Concluded that there was more tension and more evidence of egocentric feelings in a group under autocratic control, whereas 
Compartive Analysis of Job Involvemnet in Relation to Organizarional Health

Prof. B.L.Lakkanavar, Hanamant Ummanna

their work more co-operative endeavor, more expression of objective attitudes and of praise and friendliness, and more constructiveness in a group with democratic control.

\section{$>$ The Teacher}

Brown asked 300 graduates and undergraduate students in Educational Sociology to evaluate the various factors in their school experience that had been influential in the formation of personality character traits. According to their adjustment, the personalities of their teachers had been the most important single factor: 65.3 percent though this influence had been good, but 33.3 percent thought it had been unfavorable. Only about 10 percent did not consider the teachers influence important. In the line with this emphasis on the personality of the teacher, the group recommended that teachers be selected more on the basis of personality and love for children and less on the basis of mastery of subject matter.

\section{$>$ Experience}

It is well known that the attitudes are the result of one's particular biography. It has also been pointed out earlier that education in attitudes to change them in the desired direction possible. On a more purely intellectual side, attitudes are conditioned by the growth of the intelligence. Attitudes are based on perceptual experience, and their development will depend on memory, understanding, and reasoning. Ryans (1960) concluded that an increase in age and experience of teachers influenced that teacher's characteristics in the negative direction.

\section{$>$ Education}

As pointed out earlier attitudes are acquired once modification or change of attitudes is greatly influenced by the acquisition of knowledge. It is very effective through the systematic i.e, formal education.

This theoretical knowledge of factors affecting the attitudes of a person leads the present investigator to select the sex, age, experience, and qualification as the independent variable for this study.

\section{$>$ Teacher's Attitude}

Before considering what teachers can do to develop favorable attitudes in children, we should first take a look at their attitude towards children. The extreme case of the sadistic person who enjoys making people suffer can be used to illustrate the fact that people use others to satisfy their own personalized needs. One person may like teaching because it provides, an opportunity to dominate, to give the order, and to be the judge, jury, and chief executioner! Another may feel the need for excessive affection or admiration and use the pupils to obtain it. 
RJPSS Sept. 2020 Vol. XLV No.2, ISSN: (P)0258-1701 (e)2454-3403 Impact Factor: 7.717

\section{References}

https://doi.org/10.31995/rjpss.2020.v45i01.024

1. Corrigan, G.M. (1997) Action Research in a Parochial School: A Study of School Culture. Dissertation Abstracts International, 58, 6, December, Pp.1995-A.

2. David M. (1993) Job Satisfaction and the Head Teacher: A Nominal Group Approach. School Leadership and Management: Formerly School Organization. Pp. 153-164.

3. Deal T.E. and Kennedy, A.A. (1982) Corporate Cultures : The Rites and Rituals of Corporate Life, Harmondsworth, Penguin Books.

4. Derlin, R., and Schneider, G., (1994). Understanding Job Satisfaction: Principals and Teachers. Urban and Suburban. Urban Education, 29 (1), Pp.63-88.

5. Dinham, S., and Scott, C., (2000). Moving into the third Outer Domain of Teacher Satisfaction. Journal of Educational Administration, 38(4), Pp. 379-396.

6. Dixit, M. (1985) Effects of the Variables of Sex and Marital Status on the level of Job Satisfaction Among Secondary School Teachers. Journal of the Institute of Educational Research, 9, 1, Pp.22-24.

7. Egan, T.M. Yang, B., Kenneth R. (2004) The Effects of Organizational Learning Culture and Job Satisfaction on Motivation of Transfer Learning and Turnover Intention. Human Resource Development Quarterly, v15 n3 p279-301.

8. Ellen Marie Rice, Gail T. Schneider (1994) A Decade of Teacher Empowerment: An Empirical Analysis of Teacher Involvement in Decision Making, 1980-1991. Journal of Educational Administration. 32, (1), Pp.43-58.

9. Eryaman, M.Y. Mehmet G.S. (2008) A Comparative Analysis of Job Satisfaction Levels of Public and Private School Teachers. Journal of Theory and Practice in Education, 4(2), Pp.189-212.

10. Farber, B.A. (1991), Crisis in Education: Stress and Burnout in the American Teacher, Jossey-Base, San Francisco, CA.

11. Friedman, I.A., Farber, B.A. (1992), Professional self-Concept As A Predictor of Teacher Burnout. Journal of Educational Research, Vol. 86 pp.28-35.

12. Furham, A ., 1997. The Psychology of Behavior at Work. Hove: Psychology Press.

13. Garrett, H.E. (1971) Statistics in Psychology and Education. Bombay: Vakils Fefer and Simons, Ltd. 